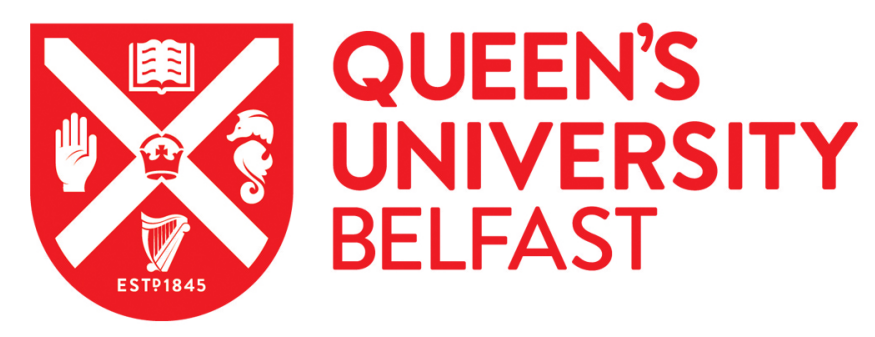

\title{
Condition-Specific Pamphlets to Improve End-of-life Communication in Long-term Care:Staff Perceptions on Usability and Use
}

\author{
Sussman, T., Kaasalainen, S., Lee, E., Akhtar-Danesh, N., Strachan, P. H., Brazil, K., Bonifas, R., Bourgeois- \\ Guérin, V., Durivage, P., Papaioannou, A., \& Young, L. (2018). Condition-Specific Pamphlets to Improve End-of- \\ life Communication in Long-term Care:Staff Perceptions on Usability and Use. Journal of the American Medical \\ Directors Association. https://doi.org/10.1016/j.jamda.2018.11.009
}

Published in:

Journal of the American Medical Directors Association

Document Version:

Early version, also known as pre-print

Queen's University Belfast - Research Portal:

Link to publication record in Queen's University Belfast Research Portal

\section{Publisher rights}

Copyright 2018 Elsevier.

This manuscript is distributed under a Creative Commons Attribution-NonCommercial-NoDerivs License

(https://creativecommons.org/licenses/by-nc-nd/4.0/), which permits distribution and reproduction for non-commercial purposes, provided the author and source are cited.

\section{General rights}

Copyright for the publications made accessible via the Queen's University Belfast Research Portal is retained by the author(s) and / or other copyright owners and it is a condition of accessing these publications that users recognise and abide by the legal requirements associated with these rights.

Take down policy

The Research Portal is Queen's institutional repository that provides access to Queen's research output. Every effort has been made to ensure that content in the Research Portal does not infringe any person's rights, or applicable UK laws. If you discover content in the Research Portal that you believe breaches copyright or violates any law, please contact openaccess@qub.ac.uk. 
1 Title: Condition-Specific Pamphlets to Improve End-of-life Communication in Long-Term Care

2 (LTC): Staff Perceptions on Usability and Use.

4 Objectives: This paper reports findings on the usability and staff use of five condition- specific pamphlets of high prevalence in LTC: dementia, heart failure, chronic obstructive pulmonary disease, renal failure, and frailty. The pamphlets were created in response to residents', families', and staff's recommendations for activating early reflections and communication about end-oflife care.

Design: A mixed-method (qualitative and quantitative) survey design was used. Step one collected survey data on the usability of the pamphlets. Step two collected survey data on pamphlet use.

Settings and Participants: Two nurses with specialized palliative care training, two resident /family representatives, ten condition-specific specialists, and 33 LTC palliative leads reviewed the pamphlets for usability prior to distribution. 178 LTC home staff in four participating LTC homes reported on pamphlet use.

Measures: Specialists and resident /family representatives were asked to provide open comments and LTC home palliative leads were asked to complete a survey on the accuracy, readability and relevance of the pamphlets. After six months of distribution, all staff in participating LTC homes were asked to complete a survey on pamphlet use, usefulness, and comfort with distribution.

Results: The pamphlets were reportedly accurate, relevant, and easy to understand. Following six months of availability, most staff in LTC had read the pamphlets, found the information useful, and planned to share them. However half of the staff questioned their role in pamphlet 


\section{4}

distribution and most had not distributed them. Regulated staff (i.e. staff affiliated with a regulated profession) expressed more comfort sharing the pamphlets than care aides and support staff.

Conclusions/Implications: Condition-specific pamphlets appear to hold promise in providing residents and families with relevant information that may activate early reflections and conversations about end-of-life care. However, structured implementation strategies, training and discussions are required to improve staff comfort with distribution, and explore roles in distribution and follow-up.

3

5

major site of death for older persons with advanced chronic conditions. ${ }^{1-3}$ Yet, the majority of older persons do not enter LTC with the primary goal of receiving end-of-life care, and consequently staff face the challenge of deciding when and how to initiate end-of-life discussions. $^{4-7}$

An important aspect of delivering holistic end-of-life care within LTC includes prompting families and residents to reflect on, discuss, and sometimes document preferences, wishes and values for future end-of-life care. ${ }^{8-9}$ These opportunities, referred to broadly as advance care planning (ACP), can reduce distress associated with in the moment decision making, and support perceptions of good end-of-life care for all parties. ${ }^{9-14}$ Despite the known benefits, ACP is rarely activated in LTC settings. ${ }^{7}$ Barriers include: reinforcing the stigma that LTC accelerates deterioration and death, uncertainty regarding when 
and how to introduce the topic, and lack of available tools to help direct reflections and discussions for conditions of high prevalence in LTC. ${ }^{7,15}$

To help staff (a) introduce the topic of disease-progression and (b) name conditionspecific issues warranting reflection and discussion, our interdisciplinary team developed five condition-specific pamphlets for conditions of high prevalence in LTC: dementia, heart failure, chronic obstructive pulmonary disease (COPD), renal (kidney) failure, and frailty. ${ }^{16}$

The idea to develop condition-specific pamphlets first evolved following analyses of 19 focus groups conducted with staff, residents, and families as part of a larger initiative aimed at strengthening a palliative approach to care. ${ }^{15}$ Analyses of these discussions revealed a desire for condition-specific pamphlets. All parties believed that such pamphlets could address barriers to ACP communication in LTC by, normalizing the importance of thinking about and discussing future care, and offering tips regarding what to anticipate, reflect on and discuss for particular conditions. This paper reports findings on the perceived usability of the pamphlets and explores how, if at all, they were used by staff. Residents' and families' use of the material are reported elsewhere. ${ }^{17}$

\section{METHODS}

This study used a mixed-method design that incorporated qualitative and quantitative survey data in two steps. In step one, data was collected from condition-specific and palliative care specialists, as well as resident/family representatives to explore the accuracy, readability, and relevance of the pamphlets. This step was used to improve the usability of the pamphlets prior to distribution and evaluation. In step two, data was collected from LTC staff in four participating LTC homes where the pamphlets were distributed. This step explored staff use of and comfort with the pamphlets. 
The four LTC homes wherein pamphlets were reviewed and distributed were located in 1 urban settings in Southern Ontario Canada. These homes were purposefully selected to represent the mix of contexts found in LTC homes across Canada ${ }^{18}$. They included for profit (three) and not for profit (one) facilities; ranged in size from large (two -169 and 206 beds respectively), medium (one -120 beds) and small (one -60 beds); included contexts with high staff turnover (two) and low staff turnover (two); and comprised of religious-based (one) and secular facilities (three).

The two steps described in this paper were conducted in accordance with the standards of the Tri-Council Policy Statement for Ethical Conduct for Research Involving Humans (2010). Procedures related to informed consent, data management, and dissemination were approved by the Office of Research Ethics Boards at X and X University.

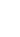

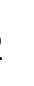

\section{Sampling and Data Collection}

\section{Step 1: Usability of Pamphlets}

We developed five paper-based 8 X 11 threefold pamphlets for medical conditions considered by staff to be most pertinent to their contexts and noted in the literature to be of high prevalence in LTC. ${ }^{16}$

Four graduate students in nursing and social work helped to develop the pamphlets in consultation with evidence-based clinical resources ${ }^{19-20}$ and the patient education literature. ${ }^{21-24}$ Based on recommendations from these resources, the students elected to include general information on the relevance of a palliative approach to care in LTC care (e.g. providing information on the importance of ACP) alongside frequently cited condition-specific information (e.g. signs and symptoms of advanced stages of a condition; resources for further condition- 
specific information). Questions to prompt further reflection and discussion were also included because this direction has been found to be an important precursor to activating discussions with clinicians. ${ }^{25-26}$ All pamphlets shared a similar structure.

Once developed, two registered nurses with combined expertise in palliative care and the LTC home sector, and two specialists associated with each of the five conditions (one nurse and one physician for each, totaling 10 condition specialists) were purposefully selected and electronically invited to provide open written comments on how well both palliative care and the conditions were described, and to review the resources named in the pamphlets. The palliative specialists reviewed all pamphlets and the condition specialists reviewed those pamphlets associated with their expertise. One resident representative and one family representative known to the team, were also asked to review the pamphlets. Finally LTC Palliative leads (regulated staff, care aides and support staff who received palliative care training as part of a larger initiative $)^{15}$ were asked to complete a seven-item paper based survey inquiring about the applicability of the pamphlets to a LTC context (e.g. easy to understand, use of non-medical language, and relevance of suggestions made). Responses to all items were scored on a Likert scale ranging from (1) strongly disagree to (5) strongly agree. The survey also invited staff to include open comments on recommended changes, and positive aspects of the pamphlets.

\section{Analysis}

We created a list of all comments provided by condition experts, palliative specialists, and resident and family representatives and categorized them into strengths, weaknesses, and suggestions. Comments categorized as weaknesses or suggestions were addressed prior to distribution to LTC palliative leads for review. 

leads as overall agreement (strong agreement and agreement) to report them as percentages and frequencies. We conducted a conventional content analysis to categorize the open survey comments provided by LTC palliative leads. ${ }^{27}$ Comments that emerged most frequently across respondents and/or that appeared to elaborate on trends noted in the quantitative findings were used to guide further pamphlet revisions.

\section{Results}

Two registered nurses with specialized palliative care training, 10 condition specialists and two resident/family representatives reviewed the pamphlets representing a $100 \%$ response rate. Their feedback suggested the information was accurate and well-described. Some provided preferred resources that were added prior to distribution to LTC palliative leads for review.

Thirty-three of the 55 eligible LTC palliative leads across four participating LTC homes completed the survey, representing a $60 \%$ response rate. Respondents included 20 regulated staff (16 nurses, 1 social worker, 1 physiotherapist, and 2 dieticians) 8 care aids, and 4 support staff (2 dietary aides, and 2 activity aides). One respondent did not identify their role within LTC. Table 1 presents staff responses to survey items.

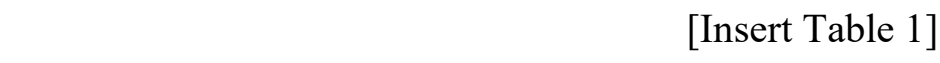

Most staff agreed the pamphlets were easy to understand, used non-medical language, and included actions that were clear and manageable. Fewer staff felt the pictures and graphs were useful, key points were easy to identify, and the font was easy to read.

Open comments reinforced and expanded on these quantitative findings. First, many staff suggested that the pamphlets were "very helpful for people with a non-clinical background", and included relevant information that is "typically not that well explained to families in LTC home 
settings". However, some staff also suggested the pamphlets were "too busy" and should include "less text, more pictures and more point form". Finally, several staff noted that relatives of LTC home residents should be referred to as family /friends rather than caregivers. The resident and

140 family representatives were consulted on this recommendation and agreed with the suggestion.

141 Consequently, most sections of the pamphlets were re-written in point form, more pictorial 142 representations were added, and references to caregivers were changed to family/friends. The

143 final iteration of the pamphlets had a reported readability index suggestive of grade seven level 144 capacity as measured by the Flesch-Kincaid, Gunning-Fog and SMOG readability instruments 145 (see: Blinded for Review).

\section{Step 2: Evaluation of Pamphlets}

\section{Sampling and Data Collection}

Over a period of six months, the pamphlets were made available to residents, and families/friends in the four participating LTC homes via bulletin displays or through distribution by staff. At study end, all staff were invited to complete a series of questionnaires on all components of the team's larger intervention program which included one survey specifically evaluating staff's perceptions and use of the pamphlets. distributing the pamphlets. Questions on pamphlet use included three items: awareness, reading, and distribution of the pamphlets. Responses were dichotomized as yes (1) or no (0). Those who had either read or distributed the pamphlets were asked to identify which pamphlets they had $\mathrm{read} /$ distributed.

Questions on perceived usefulness and comfort included six items. Items on usefulness were: usefulness of the information to self, usefulness of the information to residents/families, 
and perceived harmfulness of the information. Items on comfort were: plans to distribute in the

161 future, comfort distributing to families/friends, and feeling that one is the appropriate person to

162 distribute the information. Responses to these six items were scored on a Likert scale ranging

163 from (1) strongly disagree to (5) strongly agree. Two open ended questions on reasons for use or 164 non-use of the pamphlets were also included.

\section{Analysis} overall use, and reactions to the pamphlets. For descriptive purposes, strongly agree and agree responses for the Likert scale items on perceived usefulness and comfort were grouped together to represent agreement for an associated item and are reported as percentages and frequencies. A principal components factor analysis with varimax rotation was conducted for the six items developed to capture perceived usefulness and comfort to examine if they clustered around 173 these two pre-conceived domains. ${ }^{28}$ This allowed us to conduct Analysis of Variance comparing 174 means for perceived usefulness and comfort by occupational group: regulated staff, care aides 175 and support staff. We used Chi Square tests to examine differences in pamphlet use by occupational group for dichotomous variables. The level of statistical significance between

177 groups was specified to be $p<0.05$. Statistical analyses were performed using SPSS v23. Answers to open ended questions were categorized using a conventional content analysis 179 and then tabulated as frequencies and percentages. ${ }^{27}$ 
182

183

184

185

186

187

provides specific information about the study sample, pamphlet use, and distribution amongst staff.

\section{[Insert Table 2]}

Respondents were evenly distributed between care aides, support staff, and registered staff resembling the mix-ratios of staff in LTC. ${ }^{29-30}$ The registered staff respondents included 45 nurses, four social workers, four dieticians, three physiotherapists, one spiritual counsellor, and one physician. The support staff included 16 activity aides, 16 dietary aides, 16 maintenance staff, five physiotherapy assistants, and four clerks. Participants were largely female, had completed college degrees or higher, and had an average of 10 years of experience working in LTC.

Most staff were aware that the pamphlets were available, and had read at least one of the pamphlets, but fewer had distributed the pamphlets. Of those who read the pamphlets $(n=105)$, the dementia pamphlet was read most frequently, followed by the heart failure pamphlet.

Registered staff were more aware of the pamphlets, $X^{2}=12.96(2), p=0.002$; read more of the pamphlets, $X^{2}=18.15(2), p=0.00$; and distributed more pamphlets, $X^{2}=16.35(2), p=0.00$, than care aides, and support staff .

Most staff who had read the pamphlets suggested that the information was useful to residents and families $(83,79 \%)$, planned to share the pamphlets in the future $(76,72 \%)$, and felt comfortable sharing the information $(82,78 \%)$. Only four of them felt the information would be harmful $(4,3.8 \%)$. Despite expressed comfort only half felt they were the appropriate person to share the pamphlets $(53,50.5 \%)$ (results not shown in a table). 

Olkin (KMO) measure of sampling adequacy and Bartlett's test of sphericity. KMO is used to measure whether values have enough in common to warrant a factor analysis. Historically, values of 0.7 are considered adequate for proceeding with a factor analysis. ${ }^{31}$ Barlett's test of sphericity tests the hypothesis that items are unrelated and therefore unsuitable for further structure detection. Small values $\mathrm{p}<0.05$ indicate that a factor analysis may be useful. ${ }^{32-33}$ For our six items the p-value for Barlett's test of Sphericity was $<.01$; and KMO was $=.80$. factor analysis provided evidence for a two-factor solution (eigenvalues greater than one) which explained $70.89 \%$ of the variance.

Table 4 shows the results of mean comparisons by staff group for perceived usefulness and comfort distributing pamphlets. There were no significant differences found between occupational groups based on perceived usefulness $(\mathrm{p}=0.90)$. A significant difference was found between occupational groups related to their comfort with pamphlet distribution $(p=0.03)$. Registered staff reported higher mean comfort (Mean=12.43, $\mathrm{SD}=2.92)$ than care aides (Mean=11.06, $\mathrm{SD}=2.68)$ and support staff $(\mathrm{Mean}=10.73, \mathrm{SD}=3.03)$. Post hoc comparisons using Tukey's test suggested that this overall difference was based on the mean difference 221 between registered staff and support staff $(p=0.05)$.

Open comments revealed some important information about pamphlet distribution and 223 their use. Of the 54 participants who answered why they had used the pamphlets, almost half (26, $22448 \%$ ) suggested they used them for self-education while only a fifth (9 17\%) suggested they used 225 them to educate residents and families. The remaining comments were more general in nature 
suggesting the pamphlets were useful and informative (without specifying for whom). Comments categorized as pamphlets used for self-education included: "they helped me to increase my own knowledge"; "I wanted to know more about certain ailments and dying"; and "I wanted to be more aware about palliative care". Comments categorized as pamphlets used for educating families and residents included: "I wanted to educate families and residents to empower them to make the right decisions"; "Families seem more confident with information they can read as opposed to trying to recall something they have been told"; and "Family members benefit from education. It helps them make reasonable decisions".

\section{DISCUSSION}

Our study suggested that pamphlets are a promising method for information sharing with residents, families, and staff on what to expect and discuss regarding end-of-life care. Most staff completing the survey had read at least one of the pamphlets, had suggested the information was relevant to families and residents, and few worried about doing harm by distributing the information. Pamphlets in high demand were those addressing dementia and heart disease; two conditions of high prevalence ${ }^{16,34}$ that have been identified as particularly challenging for staff in LTC to address. ${ }^{35-36}$

Despite the high number of staff who perceived the pamphlets to be relevant, fewer staff had distributed them. The most frequent reason for non- distribution was uncertainty about

245 whether it was their role to do so. This was especially true of care aides and support staff. These 246 findings may reflect a tendency in LTC to question care aides' and support staffs' roles in end-of 247 -life care. While studies suggest that care aides and support staff provide between $70-90 \%$ of all 248 patient care in LTC, studies have also shown that these integral interdisciplinary team members 
feel disempowered to communicate their observations on resident functioning to registered staff. 28,37-41 Although it goes beyond the role of support workers and care aides to discuss prognoses with residents and families, providing them with resources and ideas regarding what they may want to discuss with one another and the health care team fits well within the caring labour they are expected to conduct. ${ }^{39-42}$

Our former work on residents' and family/friends' reactions to receiving conditionspecific pamphlets suggested that the pamphlets offer welcome opportunities for reflection but could require staff follow-up to activate discussions between residents and families/friends. ${ }^{17}$

Previous research also suggests that residents and families/friends are open to receiving written information on end-of-life from most staff in LTC including care aides, and/or staff who know them well ${ }^{43}$ Our current findings add that role uncertaintly may pose an important barrier to pamphlet distribution and follow up. Taken together these findings point to the importance of delineating the role care aides and support staff can play in pamphlet distribution and implementing a procedure to ensure follow-up by registered staff.

While clarifying roles and procedures may prove helpful to address the barrier of role confusion, it is also possible that staff's' discomfort distributing the pamphlets was related, in part, to their lack of comfort engaging in end-of-life conversations. More specifically some staff may have feared that distributing a pamphlet could place them in an uncomfortable position of fielding questions they felt ill equipped to handle. Interdisciplinary end-of-life communication training that incorporates care aides and support staff may be particularly relevant to increase comfort in this regard, because it can help to improve staff knowledge and comfort managing intense emotions whilst also providing staff with the opportunity to discuss perceived power differentials, overcome issues of trust and reflect on scopes of practice. ${ }^{44-45}$ 

structured procedures for pamphlet distribution and follow up. For example, the Palliative

Performance Scale which is a scale developed to identify when patients may benefit from end of -life care, or the 'surprise question' which prompts staff to use their clinical judgment to identify residents who could foreseeably die within a particular time frame, could be used to identify residents and families who would benefit from receiving a pamphlet ${ }^{46-47}$. Both of these triggers can be reliably used by care aides and support staff in LTC. Once a pamphlet has been provided, team huddles, rounds, or written records can communicate that pamphlet distribution has occured and follow up is warranted. Weekly on site physician visits, interdisciplinary care conferences, or daily bed-side nursing check-ins are all possible avenues for post distribution support and follow up. ${ }^{48-49}$

\section{STUDY LIMITATIONS:}

The findings from this study should be viewed in light of the following limitations. First, our factor analysis can only be considered exploratory because our sample size was small. Second, staff member perceptions were based on a self-selected sample whose experiences may not be transferable to other staff in LTC. Finally, this study was conducted in four LTC homes located in urban settings in one Canadian province limiting the generalizability of study findings to other jurisdictions. This limitation was partly addressed by our mix of LTC homes. ${ }^{17}$

\section{CONCLUSIONS/RELEVANCE}

Condition-specific pamphlets appear to hold promise in activating early reflections and conversations about end-of-life care. Such resources ensure a basic common understanding of illness related end-of-life trajectories that can prepare residents and families for more detailed discussions with staff. They also provide opportunities for all staff in LTC to play a role in 
295 priming residents and families for such discussions and have been found here and elsewhere to 296 be acceptable means of transmitting information and supporting dialogue. ${ }^{50}$ However, training 297 and facility wide deliberations may be required to, discuss staff roles in pamphlet distribution, 298 improve staff comfort engaging in end-of-life communication, and establish a consistent system 299 of pamphlet distribution and follow up. 
Author Contributions:

305

Blinded for Review

306

307

Contributions of Others: None

308

309

Sponsor's Role: None

310 
312 The authors have no conflict of interests to declare

313 Funding Sources: Blinded for Review

314

315 
1. Menec VH, Nowicki S, Blandford A, Veselyuk D. Hospitalizations at the end of life among long-term care residents. J Gerontol A Biol Sci Med Sci 2009; 64:395-402. doi: 10.1093/gerona/gln034

2. McGregor MJ, Tate RB, Ronald LA, McGrail KM. Variation in site of death among nursing home residents in British Columbia, Canada. J Palliat Med 2007;10:1128-36. doi: 10.1089/jpm.2007.0018

3. Morin L, Johnell K, Aubry R. Variation in the place of death among nursing home residents in France. Age Ageing 2015;44(3):415-21. doi: 10.1093/ageing/afu197

4. Brazil K, McAiney C, Caron-O'Brien M, et al. Quality end-of-life care in long-term care facilities: service providers' perspective. J Palliat Care 2004;20(2):85-92.

5. Johnson S, Bott MJ. Communication with residents and families in nursing homes at the end of life. J Hosp Palliat Nurs 2016;18(2):124-130. doi: 10.1097/NJH.0000000000000222

6. Parker-Oliver D, Porock D, Oliver DB. Managing secrets of dying backstage: The voices of nursing home staff. Omega (Westport) 2006;53(3):193-207. doi: 10.2190/3P8G-5JAD-J2NFBKGK

7. Cable-Williams B, Wilson D. Awareness of impending death for residents of long-term care facilities. Int J Older People Nurs 2014;9(2):169-79. doi: 10.1111/opn.12045

8. World Health Organization Europe. Palliative Care for Older People: Better Practices. 2011. http://www.euro.who.int/_data/assets/pdf_file/0017/143153/e95052.pdf. Accessed on May 31, 2018.

9. Cornally N, McGlade C, Weathers E, et al. Evaluating the systematic implementation of the 'Let Me Decide' advance care planning programme in long term care through focus groups: Staff perspectives. BMC Palliat Care 2015;14(55):1-10. doi: 10.1186/s12904-015-0051-x

10. Detering KM, Hancock AD, Reade MC, Silvester W. The impact of advance care planning on end of life care in elderly patients: a randomised control trial. BMJ 2010;340:c1345. doi: 10.1136/bmj.c1345

11. Thompson GN, McClement SE, Menec VH, Chochinov HM. Understanding bereaved family members' dissatisfaction with end-of-life care in nursing homes. J Gerontol Nurs 2012;38(10):49-60. doi: 10.3928/00989134-20120906-94

12. van Soest-Poortvliet MC, van der Steen JT, de Vet HC, et al. Comfort goal of care and endof-life outcomes in dementia: A prospective study. Palliat Med 2015;29(6):538-46. doi: $10.1177 / 0269216315570409$

13. Di Giulio P, Toscani F, Villani D, et al. Dying with advanced dementia in long-term care geriatric institutions: A retrospective study. J Palliat Med 2008;11(7):1023-8. doi: 10.1089/jpm.2008.0020

14. van der Steen JT, Gijsberts MJ, Knol DL, et al. Ratings of symptoms and comfort in dementia patients at the end of life: Comparison of nurses and families. Palliat Med 2009;23(4):317-24. doi: 10.1177/0269216309103124

15. Blinded for review

16. Hirdes JP, Mitchell L, Maxwell CJ, White N. Beyond the 'iron lungs of gerontology': Using evidence to shape the future of nursing homes in Canada. Can J Aging 2011;30(3):371-90. doi: $10.1017 / \mathrm{S} 0714980811000304$ 
17. Blinded for Review

18. Berta, W., Laporte, A., Zarnett, D., Valdmanis, V., \& Anderson, G. A pan-Canadian perspective on institutionallong-term care. Health Policy, 2006; 79(2-3), 175-194.

19. UpToDate. Waltham, MA: UpToDate Inc. 2018; http://uptodate.com

20. Pereira, J. (Ed.). The Pallium Palliative Pocketbook: a peer-reviewed, referenced resource. ( $2^{\text {nd }}$ ed.). 2016; Ottawa, ON: Pallium Canada.

21. Koh HK, Brach C, Harris LM, Parchman ML. A proposed 'Health Literate Care Model' would constitute a systems approach to improving patients' engagement in care. Health Aff (Millwood) 2013;32(2):357-67. doi: 10.1377/hlthaff.2012.1205

22. U.S. Department of Health \& Human Services: Agency for Healthcare Research and Quality. Health literacy universal toolkit (2nd ed.): Get patient feedback: Tool \#17. 2015. http://www.ahrq.gov/professionals/quality-patient-safety/quality-resources/tools/literacytoolkit/healthlittoolkit2-tool17.html. Accessed on May 31, 2018.

23. Osbourne H. Can they understand? Testing patient education materials with intended readers. On Call. 2001. http://healthliteracy.com/2001/11/01/testing-materials-with-readers/. Accessed on May 31, 2018.

24. Farrell-Miller P, Gentry P. Professional Development: How Effective Are Your Patient Education Materials? Guidelines for Developing and Evaluating Written Educational Materials. Diabetes Educ 1989;15(5):418-22. doi: 10.1177/014572178901500505

25. Sudore, R. L., \& Fried, T. R. . Redefining the "planning" in advance care planning: Preparing for end-of-life decision making. Ann Intern Med,2010;; 153, 256-261.

26. Sudore, R. L., Schickedanz, A. D., Landefeld, S., Williams, B. A., Lindquist, K., Pantilat, S. Z., ... Schillinger, D. Engagement in multiple steps of the advance care planning process: A descriptive study of diverse older adults. J Am Geriatr Soc, 2008;56, 1006-1013.

27. Hsieh HF, Shannon SE. Three approaches to qualitative content analysis. Qual Health Res 2005;15(9):1277-88. doi: 10.1177/1049732305276687

28. Pett MA, Lackey NR, Sullivan JJ. Making Sense of Factor Analysis: The Use of Factor Analysis for Instrument Development in Health Care Research. Thousand Oaks, CA: Sage Publications, 2003.

29. Kaasalainen S, Sussman T, Bui M, et al. What are the differences among occupational groups related to their palliative care-specific educational needs and intensity of interprofessional collaboration in long-term care homes? BMC Palliat Care 2017;16(33):1-8. doi: 10.1186/s12904-017-0207-y

30. Berta W, Laporte A, Deber R, et al. The evolving role of health care aides in the long-term care and home and community care sectors in Canada. Hum Resour Health 2013;11:25. doi: 10.1186/1478-4491-11-25.

31. Kaiser HF. An index of factorial simplicity. Psychometrika 1974;39(1):31-6. doi: 10.1007/BF02291575

32. Field A. Discovering statistics using SPSS. Third edition. London: SAGE publications, 2009.

33. De Vaus DA. Surveys in social research. Sixth edition. London: Routledge, 2013.

34. Daamen MA, Schols JM, Jaarsma T, Hamers JP. Prevalence of heart failure in nursing homes: a systematic literature review. Scand J Caring Sci 2010;24(1):202-8. doi: 10.1111/j.1471-6712.2009.00708.x 
35. Strachan PH, Joy C, Costigan J, Carter N. Development of a practice tool for communitybased nurses: the Health Failure Palliative Approach to Care (HeFPAC). Eur J Cardiovasc Nurs 2014;13(2):134-41. doi: 10.1177/1474515113519522

36. Hirakawa Y, Kuzuya M, Uemura K. Opinion survey of nursing or caring staff at long-term care facilities about end-of-life care provision and staff education. Arch Gerontol Geriatr 2009;49(1):43-48. doi: 10.1016/j.archger.2008.04.010

37. Kontos P, Miller KL, Mitchell GJ. Neglecting the importance of the decision making and care regimes of personal support workers: a critique of standardization of care planning through the RAI/MDS. Gerontologist 2009;50(3):352-62. doi: 10.1093/geront/gnp165

38. Fryer S, Bellamy G, Morgan T, Gott M. "Sometimes I've gone home feeling that my voice hasn't been heard": a focus group study exploring the views and experiences of health care assistants when caring for dying residents. BMC Palliat Care 2016;15(1):78. doi: 10.1186/s12904-016-0150-3

39. Miskella C, Avis M. Care of the dying person in the nursing home: exploring the care assistants' contribution. Eur J Oncol Nurs 1998;2(2):80-86. doi: 10.1016/S14623889(98)80141-5

40. Beck I, Törnquist A, Broström L, Edberg AK. Having to focus on doing rather than being Nurse assistants' experience of palliative care in municipal residential care settings. Int J Nurs Stud 2012;49(4):455-64. doi: 10.1016/j.ijnurstu.2011.10.016

41. Schell ES, Kayser-Jones J. "Getting into the skin": Empathy and role taking in certified nursing assistants' care of dying residents. Appl Nurs Res 2007;20(3):146-51. doi: 10.1016/j.apnr.2006.05.005

42. Kaasalainen S, Brazil K, Kelley ML. Building capacity in palliative care for personal support workers in long-term care through experiential learning. Int J Older People Nurs 2012; 9(2):151-8. doi: 10.1111/opn.12008

43. van der Steen, J.T., Arcand, M., Toscani, F., de Graas, T., Finetti, S., Beaulieu, M., Brazil, K., Nakanishi, M., Nakashima, T., Knol. D.L. \& Hertogh, C.M.P.M. A family bboklet about comfort care in advanced dementia: Three country evaluation. J Am Med Dir Assoc. JAMDA.2012; 13(4), 368-375.

44. Wharton, T., Manu, E., \& Vitale, C. Enhancing provider knoweldge and patient screening for palliative care needs in chronic multi-morbid patieints received home-based primary care. Am J Hosp Palliat Care. 2015; 32(1), 78-83.

45. Badger F, Plumridge G, Hewison A, et al. An evaluation of the impact of the Gold Standards Framework on collaboration in end-of-life care in nursing homes. A qualitative and quantitative evaluation. Int J Nurs Stud 2012;49(5):586-95. doi: 10.1016/j.ijnurstu.2011.10.021

46. Boscart VM, Heckman GA, Huson K, et al. Implementation of an interdisciplinary communication and collaboration intervention to improve care capacity for heart failure management in long-term care. J Interprof Care 2017;31(5):583-92. doi: $10.1080 / 13561820.2017 .1340875$

47. Rice, J., HUnter, L., Hsu, A.T., Dnskov, M., Luciani, T., Toal, Sullivan, D., Welch, V., \& Tanuseputro, P. Using the "surprise Question" in nursing homes: A prospective mixedmethods study. J Palliat Care. 2018. 33(1), 9-18.

48. Parker, D, Clifton, K, Tuckett, A, Walker, H, Reymond, E, Prior, T, McAnelly, K, Jenkin, P, Israel, F, Greeve, K \& Glaetzer. 'Palliative care case conferences in long-term care: views of 
family members.', Int J Older People Nurs, 2016 vol. 11, no. 2, pp. 140-148.View/Download from: UTS OPUS or Publisher's site

49. Tuckett, A, Parker, D, Clifton, K, Walker, H, Reymond, E, Prior, T, Jenkin, P, Israel, F, Greeve, K \& Glaetzer, K. 'What general practitioners said about the palliative care case conference in residential aged care: An Australian perspective. Part 2'. 2015; Prog Palliat Care, vol. 23, no. 1, pp. 9-17

50. Arcand M, Brazil K, Nakanishi M, et al. Educating families about end-of-life care in advanced dementia: acceptability of a Canadian family booklet to nurses from Canada, France, and Japan. Int J Palliat Nurs 2013;19(2):67-74. doi: 10.12968/ijpn.2013.19.2.67 